\title{
O mais historiador dos sociologos: Norbert Elias entre a generalização sociológica e a diferenciação histórica
}

\begin{abstract}
Resumo: O diálogo entre sociologia e história se faz presente, com toda intensidade, no pensamento de Norbert Elias (1897-1990), em razão do lugar essencial atribuído à dimensão tempo. Esse diálogo se dá por meio do confronto de duas tradições disciplinares que ora se opõem, ora se complementam: uma voltada à generalização sociológica, outra centrada na diferenciação histórica. Neste estudo, daremos ênfase às especificidades, tensões e pontos de convergência entre esses dois campos epistemológicos. Sete assertivas orientarão esta reflexão: 1) o uso errôneo dos conceitos de "indivíduo" e "sociedade"; 2) a concepção de indivíduo como homo clausus; 3) a ligação entre a história interna de cada indivíduo e a história de uma sociedade; 4) a inutilidade das teorias sociológicas que não se confirmam no trabalho empírico; 5) enquanto o estudo histórico do passado tende a impedir a comparação, o estudo sociológico tende a facilitá-la; 6) a sobrevivência de antigos conceitos e meios de expressão possibilita a compreensão de novos modos de raciocínio; 7) a violência sofre um processo de deslocamento. Concluímos, assinalando que Elias vê no saber social e no acesso à educação a possibilidade crescente de emancipação dos homens, o que supõe a reorganização das percepções histórica e sociológica.
\end{abstract}

Palavras-chave: Norbert Elias; sociologia; história; generalização sociológica; diferenciação histórica.

\section{Introdução}

A intenção de estabelecer um diálogo pertinente entre sociologia e história compõe a agenda de pensadores das ciências humanas e sociais há um tempo nada negligenciável. No campo educacional, esse diálogo é considerado essencial e tem sido posto em prática pela maioria dos estudos que elegem a educação como foco. Evidentemente, a necessidade desse diálogo não passa à margem do pensamento de Norbert Elias (1897-1990), ${ }^{1}$ como nos mostra Kirschner (2014), ao sublinhar a relevância dada pelo autor à história no quadro dos seus estudos sociológicos. Seus argumentos põem em relevo o quanto a relação entre essas duas disciplinas pode ser enriquecedora para ambas, assim como para as ciências sociais em geral. Isso pode ser observado, segundo ela, na "compreensão da relação entre indivíduo e sociedade numa perspectiva histórica, tal como fora apresentada em algumas das obras teóricas [de Elias], sendo mais visível, sobretudo, nos seus estudos dedicados a processos históricos de longa duração temporal". (KIRSCHNER, 2014, p. 62)
Ione Ribeiro Valle Universidade Federal de Santa Catarina

ione.valle@ufsc.br

1 Sobre a vida deste sociólogo alemão nascido em Breslau, destaco como central a obra Norbert Elias por ele mesmo, publicada pela Editora Zahar (2001c). Além de cinco notas biográficas e de dados biográficos do autor, apresentados na segunda parte da obra, o leitor encontra na primeira parte uma espécie de autoanálise sociológica, construída a partir de aspectos que intercalam vida e carreira. Essa perspectiva analítica é fruto de sete entrevistas realizadas com Norbert Elias por A.J. Heerma van Voss e A. van Stolk, em 1984. 
2 Ao assinalar a importância atribuída à ciência nos tempos modernos e se propor a combater

o que define como utilizações ilegítimas da ciência e do método científico, Chalmers (1987) revisita alguns pioneiros da noção de cientificidade. Seu objetivo é colocar em discussão leituras, tendências e ideologias (muitas delas de base religiosa) que insistem em reinterpretar a noção de ciência, recorrendo a conceitos duvidosos de verdade, geralmente sustentados por uma posição conservadora ou, até mesmo, ultraconservadora, os quais não se fundam em categorias próprias da ciência e dos métodos científicos.

3 Segundo Elias (2011, p. 216),

"foi demonstrado que os modelos teóricos de desenvolvimento social de longo prazo elaborados no século XIX por homens como Comte, Spencer, Marx, Hobhouse e muitos outros se fundamentaram, em parte, em hipóteses condicionadas principalmente pelos ideais políticos e filosóficos desses homens, e apenas secundariamente em suas relações com os fatos".
Como se pode ver, estamos nos referindo a um sociólogo que dedica à dimensão tempo um lugar essencial, o que o leva a considerar que o olhar do pesquisador não pode se limitar a "uma única esfera, seja ela econômica, política ou social", para não correr o risco de perder "a visão de conjunto do paralelismo da evolução". (ELIAS, 1991, p. 73) O desafio que se impõe, portanto, ao pesquisador é a complexificação crescente da investigação dos fenômenos sociais, políticos, culturais, assim como as incertezas que cercam, na contemporaneidade, a própria condição de cientificidade da ciência ${ }^{2}$.

$\mathrm{Na}$ tentativa de enfrentar essa complexificação, Elias constrói quadros analíticos multidimensionais, privilegiando uma concepção relacional. Nessa concepção, a natureza, não mais que a sociedade, está em posição de exterioridade em relação a um indivíduo considerado implicitamente como referência. O caráter multidimensional desse tipo de quadro analítico exige do pesquisador, lembra-nos Heinich (1997, p. 37), "uma grande leveza na manipulação das temporalidades múltiplas, e uma consciência aguda da sua relatividade". Isso supõe apreender injustiças ou insatisfações, percebidas no curto termo da prática intelectual, a fim de pensá-las na longa duração, em termos de gerações, coletivamente definidas, e não mais de períodos ou de anos, pertinentes à escala individual.

Apesar de priorizarmos neste momento as múltiplas facetas da relação entre sociologia e história, à luz do pensamento de Elias, não podemos deixar de assinalar que o seu trabalho, voltado à compreensão das "maneiras de viver em interdependência e num jogo constante entre o singular e o coletivo" (ELIAS, 2010, p. 218-219), exigiu uma mobilização intensa de diferentes campos do conhecimento, o que permite ao "conjunto das práticas das ciências humanas ou sociais, dos biólogos aos economistas, de se referir a uma plataforma interdisciplinar coerente num plano epistemológico". Mas essa plataforma também supõe "emancipar o arcabouço teórico da pesquisa sociológica da primazia de ideias e doutrinas sociais" (ELIAS, 2011, p. 218); prática esta que segundo ele é recorrente no pensamento clássico ${ }^{3}$.

Graças a essa opção teórico-metodológica, Elias nos legou uma obra ambiciosa e fortemente unificada: "Este estudo [referindo-se ao processo civilizador] ajuda a solucionar o renitente problema da ligação entre estruturas psicológicas individuais (as assim chamadas estruturas de personalidade) e as formas criadas por grandes 
números de indivíduos independentes (as estruturas sociais)" (2011, p. 210). A dinâmica epistemológica adotada o situa, sublinha Delmotte (2012, p. 44), como "um dos últimos generalistas, crítico da hiper-especialização nas ciências humanas e defensor de uma abordagem global, integrada, dos fenômenos sociais".

Apesar disso, sua plataforma interdisciplinar não deixa de argumentar em favor da autonomia relativa da sociologia ${ }^{4}$ no interior das ciências humanas, entendendo ser essa a única maneira de retirá-la da crise em que se encontrava. Para tanto, seria necessário avocar o que ele considerava como "o objeto específico de investigação sociológica: as transformações em longa duração das relações de interdependências entre indivíduos e grupos". (ELIAS, 2010, p. 218) Seu pressuposto é de que "existem transformações sociais que não podem ser compreendidas senão através de longas séries evolutivas, englobando várias gerações". (ELIAS, 1991, p. 17)

Ao dar preferência à compreensão das sociedades atuais e oferecer uma leitura contundente para pensar o cosmopolitismo dos tempos modernos, Elias reconhece a força do passado histórico. Por essa razão, seus estudos retrocedem "[...] longe no tempo para reconstruir os processos sociais de longa duração, os quais permitem abranger suas diferentes características". (DELMOTTE, 2012, p. 42) O objetivo principal do autor consistiu, portanto, em produzir uma sociologia histórica que coloca em evidência formas gerais de evolução. Como salienta Heinich (1997, p. 73), Elias "introduz o individual no político e a longa duração na história, introduz o passado na sociologia, as modalizações em grande escala nas ciências sociais, e a relação com o tempo como objeto de pesquisa comum a diferentes disciplinas".

A amplitude do seu quadro reflexivo nos fornece, consequentemente, uma perspectiva de análise que torna possível a apreenção de espaços sociais diversificados, de grande dimensão e em movimento; neles, as ações dos indivíduos, radicadas em cada contexto, devem ser tomadas como referência. Desse modo, ele nos aponta pistas bastante inovadoras e muito estimulantes para a produção de uma história social ou de uma sociologia histórica.
$4 \mathrm{~A}$ autonomia da sociologia em relação às demais ciências (a fisiologia ou a psicologia, por exemplo) que se ocupam apenas dos indivíduos tem grande importância para Elias (1991). Segundo ele, essa autonomia repousa sobre a autonomia relativa da qual se beneficiam as estruturas dos processos resultantes do enredamento e da interdependência dos atos de muitos indivíduos, e não de um único. 
5 A abordagem histórica empreendida por Elias foi considerada por alguns historiadores como relativamente anacrônica, face à perspectiva anteriormente adotada pela escola francesa dos Annales, fundada por Lucien Febvre (1878-1956) e Marc Bloch (1886-1944) em 1929. Estes historiadores procuraram superar a visão positivista predominante à época, pautada numa espécie de crônica dos acontecimentos (histoire événementielle), substituindo-a pela análise dos processos históricos de longa duração. No entanto, se faz necessário lembrar que $\mathrm{A}$ sociedade de corte de Elias foi elaborada no início dos anos 1930, apesar de sua circulação ter ocorrido somente no final dos 1960, o que a inscreve, do ponto de vista epistemológico, na contemporaneidade dos Annales.

\section{Duas tradições disciplinares: generalização sociológica $X$ diferenciação histórica}

Apesar das obras mais difundidas de Elias se referirem a um processo histórico plenamente identificável graças às suas demarcações espaço-temporais - o chamado processo civilizador -, seu propósito não era interpretar as particularidades desse processo, mas utilizá-lo como base para a elaboração de modelos de transformação suscetíveis a outras explicações. (AZUELOS, 2009) Tendo como objetivo fornecer delineamentos para uma teoria geral do desenvolvimento, Elias buscou na abordagem histórica de longa duração elementos para fundamentar e orientar sua reflexão sociológica, o que exigia manter um equilíbrio, ainda que inconstante, entre sociologia histórica e história de longa duração.

Certamente, ele não ignorava o fato de que para efetivar esse ambicioso empreendimento seria necessário enfrentar a generalização sociológica que se opunha, sistematicamente, à diferenciação histórica; ele também não ignorava o fato de que era preciso substituir um modelo estático e ahistórico de pesquisa por um modelo dinâmico de análise das estruturas sociais, apreendidas num continuum histórico. Ou, em outras palavras, uma nova prática tanto para a história, ${ }^{5}$ quanto para a sociologia, teria que ser inaugurada: "Elias opõe, com efeito, termo a termo, a sociologia tal como a pratica - produtora de um saber seguro, rigoroso, acumulável - e a história, perdida nos caminhos sem saída do relativismo". (CHARTIER, 2001, p. 7)

Partindo da crítica aos limites, mas também aos excessos ou às pretensões de ambas as disciplinas, Elias deixa claro que o que mais interessa não é a eliminação das fronteiras entre elas, não é a suposição de que história e sociologia devam se confundir ou se sobrepor, pois cada uma tem seus métodos, suas problemáticas, seu desenvolvimento próprio, ainda que entre elas existam complementaridades e intersecções. (HEINICH, 1997) A aposta de Elias está, sem dúvida, segundo Michon (2011, p. 12), no interesse que sociologia e história teriam

[...] em adotar uma via raramente utilizada ao longo dos dois últimos séculos: a que reconhece ao mesmo tempo plenamente a radical historicidade dos seres humanos, mas também o fato de que essa historicidade, longe de significar apenas um império 
da proliferação, do aleatório ou da dispersão, sempre implica a constituição de organizações flutuantes.

No entanto, Elias sempre teve consciência do esforço que representa enfrentar a distância entre a abordagem sociológica com pretensão científica e a realidade histórica, complexa e inesgotável. Trata-se de uma distância que decorre não raramente do fato de que, para Elias, o sociólgo deve ter a ambição de agir sobre o real - embora o quadro normativo nunca deva ultrapassar ou exceder o real, pois o retorno a ele sempre pode alterar e reorientar a teoria -, enquanto ao historiador cabe evitar esse tipo de ação. (AZUELOS, 2009, p. 5) O desafio que se impõe ao pesquisador, afirma Elias, está em conciliar a abordagem científica que inclui uma fase descritiva e explicativa com a vontade de se implicar no processo.

A saída para esse impasse ao qual se confronta permanentemente o sociólogo estaria no recurso à história, considerada como uma maneira de se distanciar do evento, sem deixar de observar certas regras de prudência. Segundo Elias, os homens, assim como os pesquisadores, são como "aprendizes de feiticeiros" , uma vez que não têm mais o controle da sua criação a partir do momento em que ela saiu de suas mãos. O estatuto de espectador engajado, próprio do sociólogo, o predispõe a se tornar um verdadeiro "caçador de mitos", ${ }^{6}$ uma vez que estes ameaçam a maioria dos pesquisadores do presente. Azuelos (2009, p. 4) traduz de maneira genérica, mas bastante pertinente, a relação do cientista social com seu objeto, nos termos de Elias: "Tudo se passa como se o discurso sociológico permitisse oferecer uma orientação à história e como se o recurso à história corrigisse a cada vez o que a démarche sociológica poderia ter de muito rígido".

Como se pode ver, a diferença entre sociologia e história não decorre da condição cronológica dos fenômenos analisados, mas do próprio princípio da análise sociológica e da especificidade primordial que a distingue da abordagem histórica. Como mostra Chartier (2001, p. 7) ao prefaciar a obra A sociedade de corte:

[...] a sociologia não consiste, ou pelo menos não exclusivamente, no estudo das sociedades contemporâneas, mas deve dar conta das evoluções de longa, até mesmo de muito longa, duração, as quais permitem compreender, por filiação ou diferença, as realidades do presente. Seu objeto é plenamente histórico, no sentido em que se situa (ou pode se situar) no passado, mas
6 Ao procurar explicitar seu entendimento sobre a sociologia o que ele desenvolve na obra "O que é sociologia?", Elias (1991, p. 83-121) dedica um capítulo à discussão dos obstáculos que enfrenta a imaginação sociológica. Ele sublinha que esta frequentemente aparece bloqueada por esquemas mentais tradicionais que levam à confusão entre o fato puramente objetivo e o juízo de valor que se tem sobre esse fato. 
7 Segundo Elias (2001a, p. 45), "os conceitos de 'indivíduo' e 'sociedade' geralmente são usados como se dissessem respeito a duas substâncias distintas e estáveis. Por esse uso das palavras, é fácil ter a impressão de que elas designam objetos não só distintos mas absolutamente independentes em sua existência. Mas na

realidade designam processos. Trata-se de processos que de fato se diferenciam, mas são indissociáveis". 8 Para Elias (2001a, p. 37), "A dificuldade de toda discussão sobre os problemas fundamentais da relação entre sociologia e história é que, até hoje, mesmo nas investigações científicas, em geral não há um esforço para definir clara e distintamente a diferença e os pontos de contato entre a evolução biológica, o desenvolvimento social e a história". seu procedimento em nada é histórico, já que não diz respeito a indivíduos, supostamente livres e únicos, mas às posições que existem independentemente deles e às dependências que regulam o exercício de sua liberdade.

Vale sublinhar que o próprio Elias, nessa mesma obra, apresenta elementos que colocam em destaque essa diferença que, na sua perspectiva, é sobretudo de grau:

[...] a pesquisa sociológica difere da história, entre outras coisas, por compreender que mesmo a formulação e seleção dos problemas singulares ficam submetidas ao arbítrio do pesquisador individual, ou às convicções convencionais heterônomas de determinados grupos de pesquisadores, a não ser que exista um mínimo de empenho em desenvolver modelos de conexão mais adequados e autônomos do que os precedentes, modelos que, restabelecendo continuamente o contato com o desenvolvimento dos dados singulares, não sejam influenciados pelas oscilações e flutuações do pensamento da própria época. (ELIAS, 2001b, p. 32)

Uma das peculiaridades do trabalho investigativo de Elias diz respeito, como se pode perceber, à relação entre o geral e o particular ou, mais propriamente, entre o indivíduo e a sociedade, apreendida na longa duração. Essa relação é fundamental à sua linha de raciocínio, pois permite reconhecer que sua obra ultrapassa toda distância epistemológica que pode haver entre sociologia e história. Em outras palavras, sua abordagem se distingue ao transgredir as fronteiras que, convencionalmente, separam os campos disciplinares. Não é por acaso portanto que ele procurou mobilizar simultaneamente diversos campos do conhecimento (sociologia, história, mas também psicologia e antropologia). ${ }^{8}$ Para levar adiante esse trabalho, Elias se empenhou na construção de um quadro reflexivo que possibilitasse o diálogo efetivo entre essas duas tradições disciplinares, mesmo reconhecendo que esse quadro acaba oscilando entre uma abordagem normativa (porque exige um certo número de traços), estrutural (porque leva em conta as características de longa duração próprias a cada grupo) e processual (porque abrange uma conjunção de mutações sociais, culturais e administrativas). 


\section{Especificidades, tensões, pontos de convergencia}

Por reconhecer a força dessas diferenças, que têm se constituído em obstáculo ao avanço científico de ambas as disciplinas, situadas no universo intelectual de uma sociologia dominada pela relativa obrigatoriedade de filiação sobretudo aos pais fundadores (Durkheim, Marx e Weber) e de uma história que ainda é a do século XX, Elias tece, de modo relativamente preciso, suas especificidades, seus pontos de tensão, seus pontos de convergência.

No que concerne à experiência sociológica, que segundo ele alcançou um alto nível reflexivo graças à ligação contínua com a pesquisa empírica individual, Elias destaca a importância do distanciamento em relação aos modelos de pensamento e de conhecimento tradicionais. Esse distanciamento se faz necessário quando o objetivo é "[...] desenvolver, ao longo das gerações, outros instrumentos de linguagem e de pensamento melhor adaptados à especificidade das interrelações humanas enquanto objeto de investigação científica". (ELIAS, 1991, p. 15) Nesse sentido, a tarefa do sociólogo consiste em "[...] identificar e compreender as diferentes formações sociais que se sucederam ao longo dos séculos". (CHARTIER, 2001, p. 15); trabalho este definido por Elias por meio da expressão Figurationsanalyse.

Em se tratando do acontecimento, Elias corrobora com a perspectiva de Paul Veyne (1998, p. 45), para quem um acontecimento não envolve um ser isolado mas o "cruzamento de itinerários possíveis". Elias o vê portanto como resultado do entrelaçamento de relações, de modo que cada virada histórica, cada fase em que parece estar em jogo o destino de um povo, se confronta com possibilidades inusitadas; toda iniciativa de um indivíduo ou de um grupo humano se mostrando atrelada a uma rede de indeterminações e de decisões aparentemente autônomas, as quais podem deslocar a configuração numa ou noutra direção. (AZUELOS, 2009) Assim, o que é posto em discussão é o fato da investigação histórica se ater principalmente às "séries de acontecimentos únicos do passado", de modo que aquilo que "é chamado de história muitas vezes parece simplesmente uma acumulação de ações isoladas de homens isolados, sem conexão entre si". (ELIAS, 2001b, p. 29-30)

Quando a intenção é abordar a relação entre as duas disciplinas, é o problema da singularidade e da unicidade dos acontecimentos que chama a atenção do sociólogo; problema este que, por se tratar 
de "um traço distintivo da história humana, do objeto da pesquisa histórica, costuma acompanhar lado a lado a ideia de que essa 'singularidade' é fundada na natureza dos objetos, ou seja, na própria coisa, independente de todos os juízos de valor dos pesquisadores". (ELIAS, 2001b, p. 35)

A preocupação com o controle dos juízos de valor, e consequentemente com o rigor da pesquisa nas ciências humanas e sociais, leva Elias a se interessar pelas múltiplas formas de envolvimento do pesquisador, a começar pela escolha do seu objeto: "Cada geração seleciona ruínas do passado e, juntando-as de acordo com seus próprios ideais e valores, faz delas casas características do seu tempo". (ELIAS, 2001b, p. 32) Os pesquisadores, alerta o sociólogo, não podem dar continuidade aos estudos, "permanecendo atolados no pântano das incertezas, caso apliquem sobre a época a ser pesquisada, sem uma postura crítica, as avaliações ideológicas, políticas e religiosas de sua própria sociedade, como se esses valores fossem óbvios". (ELIAS, 2001b, p. 53)

No caso da investigação histórica, marcada pela heteronomia dos juízos de valor, a escala de valores pessoais do historiador, condicionada por seu tempo, acaba definindo em grande medida a maneira de formular as questões e de selecionar as fontes. Parecem ser "[...] os agrupamentos extracientíficos, os partidos e ideais com os quais o pesquisador se identifica dentro de sua sociedade [que] determinam, de modo considerável, o que ele vai trazer à luz a partir das fontes históricas, o que deixará mergulhado nas sombras e como verá o nexo dos eventos". (ELIAS, 2001b, p. 31) Por essa razão, "[...] a história está sempre sendo reescrita porque a maneira como o pesquisador vê o nexo das particularidades documentadas obedece à atitude que ele assume com relação às polêmicas extracientíficas de sua época". (ELIAS, 2001b, p. 58)

A investigação sociológica, por sua vez, requer do pesquisador uma contenção mais rigorosa dos sentimentos e ideias de ordem pessoal, o que possibilita uma maior autonomia de avaliação. Seus argumentos vão portanto na direção contrária aos sistemas totalizantes que julgam o presente e profetisam o futuro. Para Elias (2011, p. 212), "[...] constitui missão de toda teoria sociológica esclarecer as características que todas as sociedades humanas possíveis possuem em comum". Como instrumento da prática social, a pesquisa sociológica somente se mostra útil quando "[...] o pesquisador não se engana projetando aquilo que deseja, aquilo que acredita que 
deve ser, em sua investigação do que é e foi". (ELIAS, 2011, p. 226) O sociólogo, segundo ele, pode ser comparado ao psicanalista da sociedade: ele a escuta, ele coleta fatos, ele tenta apontar o dedo para alguns disfuncionamentos, ele traz à tona certas contradições, ele procura fazer compreender racionalmente as verdadeiras disputas de poder de cada momento histórico com o objetivo de evitar o colapso social. ${ }^{9}$

Sua tentativa de construção de modelos sociológicos a partir de processos mais duradouros exige, consequentemente, que "[...] a autonomia do objeto de pesquisa não [seja] obliterada por juízos preconcebidos e convicções ideológicas ligadas à época do pesquisador". (ELIAS, 2001b, p. 58-59) Nesse sentido, sua abordagem parece satisfazer a exigência de complexidade e de discernimento, indispensável às análises das relações de interdependências, ${ }^{10}$ reclamadas por outros sociólogos, a exemplo de Pierre Bourdieu.

Empenhado em controlar o risco das avaliações apressadas e das ideias de curta duração, decorrentes muitas vezes de conflitos profundos vividos no presente, as quais se tornam rapidamente inoperantes, Elias recusa toda explicação monocausal e unilateral do desenvolvimento social, apreendendo-o como um processo social ${ }^{11}$ evolutivo mais amplo e sempre aleatório, ainda que estruturado e orientado. Segundo ele, essas avaliações e ideias acabam servindo de "substitutos para as teorias relativamente autônomas, para os modelos de correlação passíveis de verificação", que precisam ser "considerados em conjunto com a aquisição de novos conhecimentos singulares". (ELIAS, 2001b, p. 32)

Seu trabalho busca portanto uma solução para a complexa equação entre o pressuposto universalista, inerente ao movimento histórico, e o relativismo histórico que pode resultar de uma concepção que procura não dar a devida atenção às eventualidades. Isso o leva a recriminar os sociólogos pela sua fixidez, pela sua extrema dependência e determinismo, em razão da sua incapacidade para apreender a profundidade histórica. A dificuldade estaria em reconhecer que os processos de transformação social, notadamente os não planificados, não têm um começo, não têm um fim, nem um ponto de partida, nem um ponto de chegada, que toda evolução, seja qual for, é parcialmente reversível, não se opera forçosamente em linha direta e "[...] comporta numerosos retornos
9 Segundo Azuelos (2009, p. 3), "Elias explicita sua ambição de querer ser uma espécie de médico do social, entendendo ser uma das tarefas do sociólogo a prevenção de algumas catástrofes".

10 No intuito de tornar claras as questões postas pelo sociólogo e pelo historiador, Elias (2001a, p. 158) formula o conceito de interdependência, fazendo referência ao jogo de xadrez no qual "cada ação decidida de maneira relativamente independente por um indivíduo representa um movimento no tabuleiro social, jogada que por sua vez acarreta um movimento de outro indivíduo - ou, na realidade, de muitos outros indivíduos -, limitando a autonomia do primeiro e demonstrando sua dependência".

11 Para exemplificar a amplitude de sua noção de processo social, Elias recorre à abordagem parsoniana, fazendo alusão ao reducionismo decorrente da natureza estática dos seus conceitos: "Em vez de um processo relativamente complexo, mediante o qual a vida afetiva das pessoas é gradualmente levada a um maior e mais uniforme controle de emoções - mas certamente não a um estado de total neutralidade afetiva -, Parsons sugere uma simples oposição entre dois estados, afetividade e neutralidade afetiva, que supostamente estariam presentes em graus diferentes em diferentes tipos de sociedade, tal como quantidades diferentes de substâncias químicas". (ELIAS, 2011, p. 212) 
para trás, desvios e ziguezagues" (HEINICH, 1997, p. 67), e que toda tendência histórica é acompanhada de contra-tendências inversas.

Em relação ao historiador, Elias assevera que toda pesquisa histórica centrada em torno da singularidade e da individualidade deve explicitar com clareza as ideias acerca da dependência e da independência entre os homens. O historiador, nessa perspectiva, nunca pode, como ambicionam certos sociólogos, basear-se completamente em regularidades de tipo científico, ainda que elas possam ser reconhecidas como úteis. Ainda que "[...] apoiada na prática documental e nas exigências técnicas da erudição, essa maneira de agir só é capaz de produzir um saber arbitrário, constituído por uma sucessão de juízos contraditórios, todos reflexo dos interesses e partis pris dos historiadores que os emitem". (CHARTIER, 2001, p. 7)

O que torna praticamente irrealizável a formulação de uma sociologia histórica e de uma história sociológica, segundo Elias, é o tipo de percepção analítica que acaba dando ênfase a eventos singulares e elegendo "[...] figuras históricas individuais, como um primeiro plano bem nítido, diante dos fenômenos sociais, como um segundo plano visto de modo relativamente desestruturado" (ELIAS, 2001b, p. 51) ou, até mesmo embaçado. Ou seja, o desafio está em buscar uma efetiva reciprocidade entre essas duas tradições disciplinares.

\section{Reciprocidades e complementações epistemologicas}

A perspeciva relacional que predomina hoje nas ciências humanas e sociais, e que resultou de rupturas epistemológicas inauguradas por investigadores de diferentes áreas do conhecimento, não consegue mais conviver com a rigidez imposta pelas convencionais fronteiras disciplinares, edificadas num momento histórico de consolidação das ciências em geral e de cada ciência em particular. Parece consenso entre os pesquisadores, particularmente entre historiadores e sociólogos, a necessidade de superar antagonismos, de estabelecer reciprocidades e de buscar complementaridades, visando enfrentar a complexidade dos seus objetos. Como vimos anteriormente, a obra de Elias se inscreve nesse quadro de referência sendo possível destacar algumas assertivas, centradas na compreensão de conceitos frequentemente opostos: 
autonomia/heteronomia, independência/dependência, autocontrole pulsativo/controle. (MARTUCCELLI, 2000)

O uso errôneo dos conceitos de "indivíduo" e "sociedade" está ligado a uma ilusão de ótica. A dicotomização desses conceitos impõe limites consideráveis ao modus operandi tanto de sociólogos, quanto de historiadores. Elias (2001b, p. 51-52) observa que "A maneira pela qual certos sociólogos concebem seu trabalho leva a pensar que eles se ocupam exclusivamente de figurações, e de figurações sem indivíduos, de sociedades ou 'sistemas' que são totalmente independentes dos homens singulares, em todos os sentidos". E não é diferente com a pesquisa histórica: "[...] a maneira pela qual certos historiadores concebem seu trabalho leva a pensar que eles se ocupam exclusivamente de indivíduos e, muitas vezes, de indivíduos sem figuração, de homens que são totalmente independentes uns dos outros, em todos os sentidos" (ELIAS, 2001b, p. 51-52).

A concepção de indivíduo como homo clausus, como um pequeno mundo em si mesmo, determina a imagem do homem em geral. Para Elias, o homo clausus, pensado como ser e não como dever ser, é um mito. E é em contraposição a esse mito que ele procura desenvolver sua própria concepção de indivíduo no plural, de indivíduo que interage com os outros indivíduos numa configuração aberta e sempre em movimento, sempre em processo. É importante assinalar que Elias foi sempre muito cético em relação ao poder dos grandes homens em reverter o movimento da história, embora não deixe de reconhecer que esses homens possam ter influência sobre o curso dos acontecimentos.

A história de uma sociedade se reflete na história interna de cada indivíduo. Esta premissa pode ser percebida claramente na ideia de Elias (1991, p. 34) de que "o homem não é jamais um começo. Todo homem é um herdeiro". Assim, fica evidenciada a complexidade do estudo histórico, a qual remete à necessidade de desconfiar das reconstruções produzidas $a$ posteriori, particularmente daquelas que evocam um progresso contínuo e regular em direção à "perfeição". Ou, nos termos de Chartier (2001, p. 9), é preciso tomar "distância em relação a uma sociologia mais tentada pela construção de taxinomias de validade universal do que pela 'análise intensiva' de casos históricos determinados". Isso, no plano metodológico - quando 
12 Journet (2000), ao analisar o pudor, a polidez e a civilização em Elias, destaca a importância atribuída a uma moral puritana, que corresponde à higiene. Segundo ele, Elias observa um movimento crescente das pulsões físicas e emocionais, traduzidas no autocontrole de cada um por si mesmo, sobretudo em relação aos contatos corporais, à sexualidade e à violência. É essa interiorização crescente das normas que torna cada vez mais desnecessários os mecanismos sociais de repressão. o objetivo é apreender o tempo longo, as interdependências, as formas de estruturações intermediárias, as formas de incorporação do social pelos indivíduos - significa levar efetivamente e criticamente em conta as fontes empíricas, os procedimentos propostos, os conceitos a serem mobilizados, as modalidades de escrita a serem adotadas.

Teorias sociológicas que não se confirmam no trabalho empirico são inúteis. Segundo Chartier (2001, p. 11), Elias "Constrói um modelo de interpretação sociológica que pretende se diferenciar daqueles que dominavam a sociologia alemã do início dos anos 30". Sua intenção era dispor de recursos para organizar o conjunto de dados históricos coletados durante suas leituras. Neste sentido, os procedimentos metodológicos ganham relevância, pois, na perspectiva elisiana, "o estudo de caso permite atingir o essencial, ou seja, o esclarecimento das condições que tornam possível a emergência e perpetuam a existência de uma tal forma social". (CHARTIER, 2001, p. 9) Ou seja, o estudo de caso permite apreender aspectos culturais, preservados no silêncio dos gestos e das práticas cotidianas.

Enquanto o estudo histórico do passado tende a impedir a comparação, o estudo sociológico tende a facilitá-la. A perspectiva analítica de Elias privilegia os recursos metodológicos comparativos, os quais permitem pôr em evidência as semelhanças ou as diferenças entre sociedades contemporâneas, ou entre momentos diferentes de uma mesma sociedade. Segundo Elias (2001a, p. 29), "A investigação de uma certa sociedade de corte do passado também oferece uma contribuição para o esclarecimento de extensos problemas sociológicos acerca da dinâmica social". Além disso, ele considera que os estudos comparativos, ao se centrarem sobre uma determinada sociedade de corte, tornam possível a produção de modelos para interpretar as diversas sociedades de corte. Todavia, seu propósito não é promover uma análise sincrônica, "mas situar a duração e os ritmos próprios da evolução das formações sociais" (CHARTIER, 2001, p. 15), sem deixar de considerar que uma duração e um ritmo não são facilmente perceptíveis.

A sobrevivência dos antigos conceitos e meios de expressão sempre possibilita a compreensão dos novos meios de expressão ou modos de raciocínio. Elias $(1991$, p. 17, 19) reconhece que "as ciências 
socias têm talvez mais que outras a liberdade de criar um novo vocabulário e novos conceitos". Mas ele também reconhece que essa liberdade tem limites, pois, ao se distanciar excessivamente, corre-se o risco de tornar impossível toda comunicação. Por essa razão, ele defende que "é preciso reorganizar a percepção $\boldsymbol{e}$ o pensamento de um grupo de homens interdependentes no seio de uma sociedade."

Graças a monopolização pelo Estado e sua interiorização, a violência sofre um processo de deslocamento. Para compreender esse processo, Elias procura introduzir a dinâmica individual de socialização (a psicogênese) no quadro mais amplo da gênese do estado (a sociogênese). Seu objetivo é mostrar que, na formação do habitus nacional, a transmissão de uma memória se dá na longa duração e é incorporada em cada cérebro, gerando uma mentalidade particular. ${ }^{12}$ Segundo Martuccelli (1999, p. 235), a noção de socialização ganha força na lógica de racionalização interpretada por Elias. Nela, a socialização visa a constituição de uma segunda natureza - tal como o processo de civilização -, a qual se efetiva por meio do prolongamento da escolarização. A tentativa de apreender essa dinâmica leva Elias a formular, assim como fizera Bourdieu, o conceito de habitus. Elias concebe habitus como o conjunto dos comportamentos ou das idiossincrasias de um povo ou de um grupo humano. Ele nunca é fixo, mas sempre deve remeter ao processo de formação do Estado no qual está implicado o povo ou o grupo considerado.
12 Journet (2000), ao analisar o pudor, a polidez e a civilização em Elias, destaca a importância atribuída a uma moral puritana, que corresponde à higiene. Segundo ele, Elias observa um movimento crescente das pulsões físicas e emocionais, traduzidas no autocontrole de cada um por si mesmo, sobretudo em relação aos contatos corporais, à sexualidade e à violência. É essa interiorização crescente das normas que torna cada vez mais desnecessários os mecanismos sociais de repressão.

\section{Concluindo...}

A título de conclusão desta breve reflexão, recorremos ao desafio que se impôs o próprio Elias (2014, p. 19): "Eu trabalho ainda hoje para compreender como mudanças de longa duração podem se produzir sem que ninguém tenha formado o projeto ou a intenção. Isso permanece ainda para ser explicado". Esta sua afirmação remete ao empenho deste pensador em nos legar "uma obra cujo vigor inovador o tempo não apaga". (CHARTIER, 2001, p. 8) Não podemos deixar também de sublinhar o seu esforço em nos proporcionar "os alicerces de uma teoria sociológica não dogmática, empiricamente baseada, de processos sociais em geral e de desenvolvimento social em particular". (ELIAS, 2011, p. 209) 
Sua contribuição se revela de uma grande riqueza exegética ao delinear uma sociologia histórica de grande envergadura, que instiga sociólogos e historiadores a perceberem a importância de uma determinada formação social, independentemente de a apreciarem ou não; ao estabelecer uma conexão entre essas duas tradições epistemológicas, uma podendo ser facilmente tomada pela outra, em razão dos modos predominantes de pensamento.

Embora Elias assinale que é um equívoco pensar que é nos livros que se aprende o máximo das coisas pois ele as aprendeu com as épocas que atravessou e com as pessoas com quem conviveu, Chartier (2001, p. 25, grifo do autor) nos ajuda a perceber a força inovadora dos seus livros. Ele assinala que numa

[...] época em que a história reduziu as dimensões de seus campos de estudo, privilegiando a monografia, o estudo de caso ou a 'micro-história', eles lembram, ao lado de alguns outros, que certas evoluções fundamentais são compreendidas apenas em ampla escala, na longa duração da sucessão das formações sociais e das transformações das estruturas psicológicas. E em uma época em que a história fragmentou suas abordagens, fechou seus objetos, a obra de Elias salienta o risco de um tal despedaçamento colocando como problema essencial o vínculo existente com as formas sociais, os habitus psíquicos, as produções estéticas... É preciso lê-lo, como os clássicos, inscrevendo-o em seu tempo e, ao mesmo tempo, escutando-o no presente.

Como se pode ver, o legado de Elias remete às Luzes, embora muitos dos pressupostos mobilizados visando a edificação da sua obra o distanciem do pensamento iluminista. Martuccelli (1999), a exemplo de outros comentadores, observa que a teoria eliasiana estabelece uma relação muito estreita, e no fundo positiva, entre a extensão do saber e o processo de racionalização.

Enfim, parece evidente que Elias vê no saber produzido socialmente e na sua ampliação - o que nas sociedades contemporâneas se dá sobretudo graças ao prolongamento da escolarização - a possibilidade crescente de emancipação dos homens. Ao fazer uma aposta irrepreensível no saber e no acesso a ele, sua abordagem incita a submeter a todo o momento a crítica a função social da escola, mas também a da formação universitária. Isso exige de nós pesquisadores, interessados sobretudo nas questões que configuram 


\title{
An historian-like sociologist: Norbert elias between sociological generalization and historic differentiation
}

\begin{abstract}
The dialog between sociology and history is intensely present in the thinking of Norbert Elias (1897-1990), due to the essential place he attributes to the dimension of time. This dialog occurs by confronting two disciplinary traditions that are at times opposed and at times complementary: one focused on sociological generalization, another on historic differentiation. In this study, we emphasize the specificities, tensions and points of convergence between these two epistemological fields. Seven assertions guide this reflection: 1) the concepts of "individual" and "society" are often used erroneously; 2) the concept of individual as homo clausus; 3) the connection between the internal history of each individual and the history of a society; 4) the uselessness of sociological theories that are not confirmed by empiric work; 5) while the study of history of the past tends to impede comparison, sociological study tends to facilitate it; 6) the survival of old concepts and means of expression allow understanding new modes of reasoning; 7) violence suffers a process of dislocation. We conclude by indicating that Elias sees in social knowledge and in the access to education a growing possibility for emancipation of humans, which supposes the reorganization of the historic and sociological perceptions.
\end{abstract}

Key-words: Norbert Elias; sociology; history; sociological generalization; historic differentiation.

\section{El más historiador de los sociólogos:Norbert elias entre la generalización sociológica y la diferenciación histórica}

Resumen: El diálogo entre sociología e historia se hace presente, con toda intensidad, em el pensamiento de Norbert Elias (1897-1990), en razón al lugar esencial atribuido a la dimensión tiempo. Ese diálogo se da por medio de la confrontación entre dos tradiciones disciplinares que a veces se oponen y a veces se complementan: una orientada a la generalización sociológica, otras centrada en la diferenciación histórica. En este estudio, haremos énfasis em las especificidades, tensiones y puntos de convergencia entre estos dos campos epistemológicos. Siete aserciones orientarán esta reflexión: 1) el uso erróneo de los conceptos de "individuo" y "sociedad": 2) la concepción de individuo como homo clausus; 3) la conexión entre historia interna de cada individuo y la historia de una sociedad; 4) la inutilidad de las teorías sociológicas carentes de confirmación empírica; 5) mientras que el estudio histórico del pasado tiende a impedir la comparación, el estudio sociológico tiende a facilitarla; 6) la supervivencia de antiguos conceptos y medios de expresión hace posible la comprensión de nuevos modos de raciocinio; 7) 
la violencia sufre un proceso de deslocalización. Concluimos aseverando que Elias ve en el saber social y en el acceso a la educación la posibilidad creciente de emancipación humana, lo que supone la reorganización de las percepciones histórica y sociológica.

Palabras clave: Norbert Elias; sociología; historia; generalización sociológica; diferenciación histórica

\section{Referências}

AZUELOS, D. Norbert Elias entre sociologie et histoire. Archive ouverte en Sciences de l'Homme et de la Société, Paris, p. 1-6, avril 2009. Disponível: https://halshs.archives-ouvertes.fr/halshs-00392021. Acesso em: 9 fev. 2020.

CHALMERS, A. F. Qu'est-ce que la science? Popper, Kuhn, Lakatos, Feyerabend. Paris: La Découverte, 1987.

CHARTIER, R. Prefácio. Formação social e economia psíquica: a sociedade de corte no processo civilizador. In: ELIAS, N. A sociedade de corte. Investigação sobre a sociologia da realeza e da aristocracia de corte. Rio de Janeiro: Zahar, 2001. p. 7-25.

DELMOTTE, F. La sociologie historique de Norbert Elias. Cahiers Philosophiques, Paris, n. 128, p. 42-58, 2012.1. Disponível: : https:// www.cairn.info/revue-cahiers-philosophiques-2012-1-page-42.htm. Acesso em: 15 mar. 2020.

ELIAS, N. et al. La sociologie... quand elle est bien faite. Entretien Johan Heilbron, 1984-1985. Actes de la recherche en sciences sociales, Paris, n. 205, p. 4-19, 2014/5. Disponível: https://www.cairn.info/ revue-actes-de-la-recherche-en-sciences-sociales-2014-5-page-4.htm. Acesso em: 9 maio 2020.

ELIAS, N. et al. Norbert Elias et le $20^{\mathrm{e}}$ siècle. Le processus de civilisation à l'épreuve. Comptes rendus d'ouvrages autour de Norbert Elias. Vingtième siècle. Revue d'histoire, n. 106 (spécial), p. 215-233, 2010/2. Disponível: https://www.cairn.info/revue-vingtieme-sieclerevue-d-histoire-2010-2-page-215.htm. Acesso em: 10 abr. 2020.

ELIAS, N. A sociedade de corte. Investigação sobre a sociologia da realeza e da aristocracia de corte. Rio de Janeiro: Zahar, 2001a.

ELIAS, N. Apêndice. Introdução à edição de 1968. In: ELIAS, N. O processo civilizador. 2. ed. Rio de Janeiro: Zahar, 2011. p. 205-241. (Uma história dos costumes, 1).

ELIAS, N. Introdução: sociologia e história. In: ELIAS, N. A sociedade de corte. Investigação sobre a sociologia da realeza e da aristocracia de corte. Rio de Janeiro: Zahar, 2001b. p. 27-59.

ELIAS, N. Norbert Elias por ele mesmo. Rio de Janeiro: Jorge Zahar Editor, 2001c.

ELIAS, N. Qu'est-ce que la sociologie? La Tour d'Aigues: Éditions de l'Aube, 1991. 
HEINICH, N. La sociologie de Norbert Elias. Paris: La Découverte, 1997.

JOURNET, N. Pudeur, politesse et civilisation. Norbert Elias s'est-il trompé? La sociologie. Histoire et idées. Auxerre: Sciences Humaines Éditions, 2000. p. 159-164.

KIRSCHNER, T. C. História e sociologia: a contribuição de Norbert Elias. História e Cultura, Franca, v. 3, n. 3 (Especial), p. 53-65, dez.

2014. Disponível: https://www.periodicos.franca.unesp.br/index.php/ historiaecultura/article/download/1409/1297.

MARTUCCELLI, D. La notion d'individu chez Norbert Elias. Tumultes, n. 15, p. 45-66, out./dez. 2000. Disponível: https://www.jstor.org/ stable/24596698?seq=1\#page_scan_tab_contents.

MARTUCCELLI, D. Norbert Elias, la rationalisation comme autocontrôle. In: MARTUCCELLI, D. Sociologies de la modernité. Litinéraire du XX siècle. Paris: Éditions Gallimard, 1999. p. 231-259.

MICHON, P. La sociologie historique de Norbert Elias à la lumière du rythme. Rhuthmos, p. 1-14, juin 2011. Disponível: http://www. rhuthmos.eu/spip.php?article363.

VEYNE, P. Como se escreve a história; Foucault revoluciona a história. Brasília, DF: EdUnB, 1998. 